\title{
Research on Penetrability of Project-based Learning in Ecological Classroom
}

\author{
Xiaoli Zhao \\ Primary Education College \\ Linyi University \\ Linyi, China
}

\begin{abstract}
Information technology course aims at improving students' information skills and literacy. The integration and intergrowth of the ecological classroom with information technology and the project-based learning, and how to use project-based learning in teaching to improve students' information literacy as well as how to make students more efficiently grasp other skills related to the information technology course are elaborated.
\end{abstract}

Keywords-ecological system; ecological classroom; projectbased learning; project plan

\section{INTRODUCTION}

The function of education refers to the function and value of education to train people. Modern education cannot only focus on the learning of knowledge in textbooks but on the promotion of people's integrated development including correct outlook on life, values, survival skills and emotional attitudes as well as the respect for life. How to profoundly reflect the new connotation of modern education for students?

Students receive education directly in the classroom. What kind of classroom can embody the function of modern education? What kind of teaching methods can be used in the classroom to achieve good effects? The answer is the penetrability of ecological classroom in project-based learning.

\section{COMPONENTS OF ECOLOGICAL CLASSROOM}

\section{A. Ecology and Ecological System}

The word "ecology" derives from ancient Greek, referring to "residence" or "habitat" originally. In 1866, German biologist E. Haeckel first proposed the ecology and defined it as "the relationship between organism and the surrounding". [1]

Ecological system is the unified whole constituted by biological community and inorganic environment. It refers not only the natural ecological system biologically but also the artificial ecological system, even the dynamic open systems with self-organization in the nature. The biggest ecological system in the nature is the biosphere. People mainly live in the artificial ecological system with cities and farms.

\section{B. Classroom Ecosystem}

The unique thoughts of people highlight the differences of people. The traditional cramming education eliminates the differences and leads to the education like quantity production. We assume students are in zero state in the traditional cramming education. The value will increase within limits with the embodiment of students' autonomy in class. The ideal results will not be achieved and the class will lose its significance if students are too independent in class. A vital classroom with good balance should be built to make students internalize the external knowledge. As early as the 17th century, Czech educator Comenius emphasized in the Great Didactica that the comprehensive school must be pleasant, thorough and rapid. The pleasant means "no whip, asperity or compulsivity... the implementation should be mild and relaxed"; the thorough means "the education is not hypocritical and superficial but real and internal to make students understand and use what they learn"; the rapid means "the education is not labored but very relaxed. Classroom teaching has four hours everyday. A teacher can teach hundreds of students at the meantime and now has to work ten times harder to teach one students". [2] The theory proposed four centuries before describes the quintessence of ecological classroom that is natural, real, relaxed and harmonious.

Classroom ecosystem is a part of artificial ecological system. Ecological classroom is the concrete embodiment of classroom ecosystem, including biological factor and nonbiological factor. The former contains educator and educatee; the latter contains complicated contents. Except for the cultural factor of teaching contents, it also includes other cultural factors such as the degree of teachers' familiarity with educational contents, extension range and whether students are interested in the contents, interpersonal factors such as the communication between students, and the classroom atmosphere, emotional factors such as humanistic care, and physical factors such as whether the position of students in the classroom avails the communication between teachers and students and between students and the light and cleanliness of the external environment. There are three dominant factors in the classroom ecosystem, two biological factors of educator and educatee and one non-biological factor of teaching contents, forming the ternary relation of ecological classroom. Teachers absorb educational contents in preparing lessons and teach it to students, and then obtain the feedback information 
via process assessment and summative assessment as well as communication. Teachers expand and improve educational contents according to the feedback information. Inevitably, it includes students' independent learning and expansion, which will embody in the feedback information. The independent expansion of students is not absolutely right and requires teachers to assist and correct. The biologic chain relationship formed by the three is the most fundamental element in the classroom ecosystem.

According to the three dominant factors in the ecological classroom, American scholar Tharp R develops five standards of optimization of classroom teaching to measure whether the collaboration of educator, educatee and educational contents reaches the standard [3]:

- Teachers and students participate in creative activities together.

- Give play to the language and cultural literacy of learners.

- Teaching connects with the life of students.

- Teach students the complicated thinking skills.

- Teach through dialogue.

The five standards reflect the exploration, equality, awakening, effectiveness and respect for the ecological classroom.

The realization of ecological classroom must abandon the traditional "teacher-oriented classroom" and create "studentoriented classroom". Unlike other biology, teachers and students neither directly depend on nor completely belong to the environment. They continuously change and improve the classroom ecosystem in building the ecological classroom.

\section{Characteristics of Ecological Classroom}

The characteristics of ecological classroom are as follows:

- Democracy and equality. Democracy embodies the ecological classroom respects individual life. Equality exists between students and between teachers and students.

- Nature and harmony. It emphasizes the natural classroom situation and harmonious atmosphere.

- Independence and cooperation. It embodies the independent learning of students and the cooperation between teachers and students and between students.

- Exploration and production. Produce new thought in exploring knowledge skills.

- Openness and selection. Teaching design and project selection are open.

- Multiple evaluation methods and personalized development.

\section{PROJECT-BASED LEARNING}

\section{A. Project-based Learning}

Project-based learning is PBL for short. The original forms of PBL are the European reformatory education in the 18th century and the American cooperative education in the 19th century. It became an important theoretical trend of thought in the middle and later periods of the 20th century. In 1941, Tyler proposed the Tyler Rationale to design, organize and implement assessment according to the advance provision and educational objectives, in order to determine the dimensionality of educational objectives reached by students through teaching. Tyler Rationale reflects the elements of PBL. The design includes three problems in designing teaching unit plan, threedimensional object and curriculum framework: content problem, unit problem and basic problem. The organization of teaching corresponds to the whole teaching process of PBL, including deal with the relationship among three elements in ecological classroom. The assessment includes formative assessment and summative assessment. PBL has been put into practice. Although no unified definition about it forms, the definitions proposed by Buck Institute for Education and Chinese scholar Li Jiahou elaborate the same point that students are encouraged to explore in PBL with the help of project activities to improve their ability. It is a typical studentoriented teaching method that gives students the main theme and lets them choose specific project contents. PBL is broader and opener concept than task-based learning and lets students be accustomed to a complete way in solving problems. The "project" contains knowledge of many courses. Teachers assign independent project to students to collect information, design scheme, implement the project and evaluate. Students understand the basic requirements of the whole process and each link after completion of this project.

\section{B. Essential Characteristics of PBL}

1) Student-oriented independent learning:"Independent learning" and "passive learning" are opposite. "Independent learning" is student-oriented and emphasizes the initiative, strategy, correction and feedback of learning; "passive learning" is teacher-oriented learning that students learn passively and mechanically. The initiative learning means students have initiative learning motivation instead of being forced by external factors and their willingness to establish relationship between the information received by them and the old experience. The strategy emphasizes students' selfadjustment ability and the ability to choose strategies to solve problems. Correction means students correct knowledge and improper strategies in learning activities. Feedback reflects the value of learning evaluation as feedback information for teachers.

2) Situation-based cognitive learning: Situated cognition is proposed by cognitive psychologists, normalizing the cognition of emotional factor and environmental factor in the ecological classroom and regarding knowledge as the tool to know the world. According to the theory of situated learning, the learning means learners bring new information in the logical frame (memory, experience and reaction of the internal 
world) of their own. [5] Situated cognition emphasizes integrating more social, cultural, physiological and psychological experience of various forms to achieve the ideal learning effect. It conforms to the external factors in ecological classroom. In conclusion, situated learning emphasizes two learning principles: first, present knowledge and combine learning and application in knowledge application, let learners think and practice like experts; second, learn through social interaction and collaboration.

3) Multiple intelligent learning: Gardner established the multiple intelligence theory that divides human intelligence into linguistic intelligence, logical intelligence (mathematical skills), musical intelligence, body intelligence (sports skills), spatial intelligence, interpersonal relationship intelligence and intrapersonal intelligence according to the people's way of thinking. [6] The theory advocates the mutual influence and development of multiple intelligences and sharply criticizes the traditional teaching like quantity production.

4) Generative learning: Generative learning is the form under the perspective of generative thinking, referring to the process that teachers and students establish teaching activities independently according to different learning situations. It includes four factors: generation, motivation, attention and previous experience. In order to achieve the result of generative learning, teachers pay attention to expressive objectives, teaching process, teaching events, interactive teaching methods and the added value of teaching process.

\section{The Design OF APPLYING PBL to ECOLOGICAL CLASSROOM}

According to the constructivism learning, students are cognitive subject, receive new knowledge and recombine it with old knowledge. Teachers play the role of guiding in this process. The educational world has been exploring how to give play to the role better. The application of PBL in ecological classroom cannot thoroughly solve this problem, but compared with the traditional teaching method, it avails students to actively explore in the natural, real, relaxed and harmonious classroom. The integration of the two can embody the intergrowth of ecological system and the original intention of design teaching.

\section{A. Analysis on the Current Situation of Providing Information Technology Curriculum}

On biological factor in ecological classroom, teachers need to extend knowledge. They cannot break the traditional limitation only through improvement of teaching methods: the demonstration and teaching fails to highlight the studentoriented learning. Obviously, the teaching method will not train students' ability in independent learning.

On non-biological factor in ecological classroom, the school has constructed multi-media classrooms and computer rooms, but the arrangement of students' position is unreasonable. Although it overcomes the arrangement like "rice seedling bed", compared with the shape of "ring", the shape of "head-to-head" fails to form harmonious classroom relationship.

\section{B. Design of $P B L$}

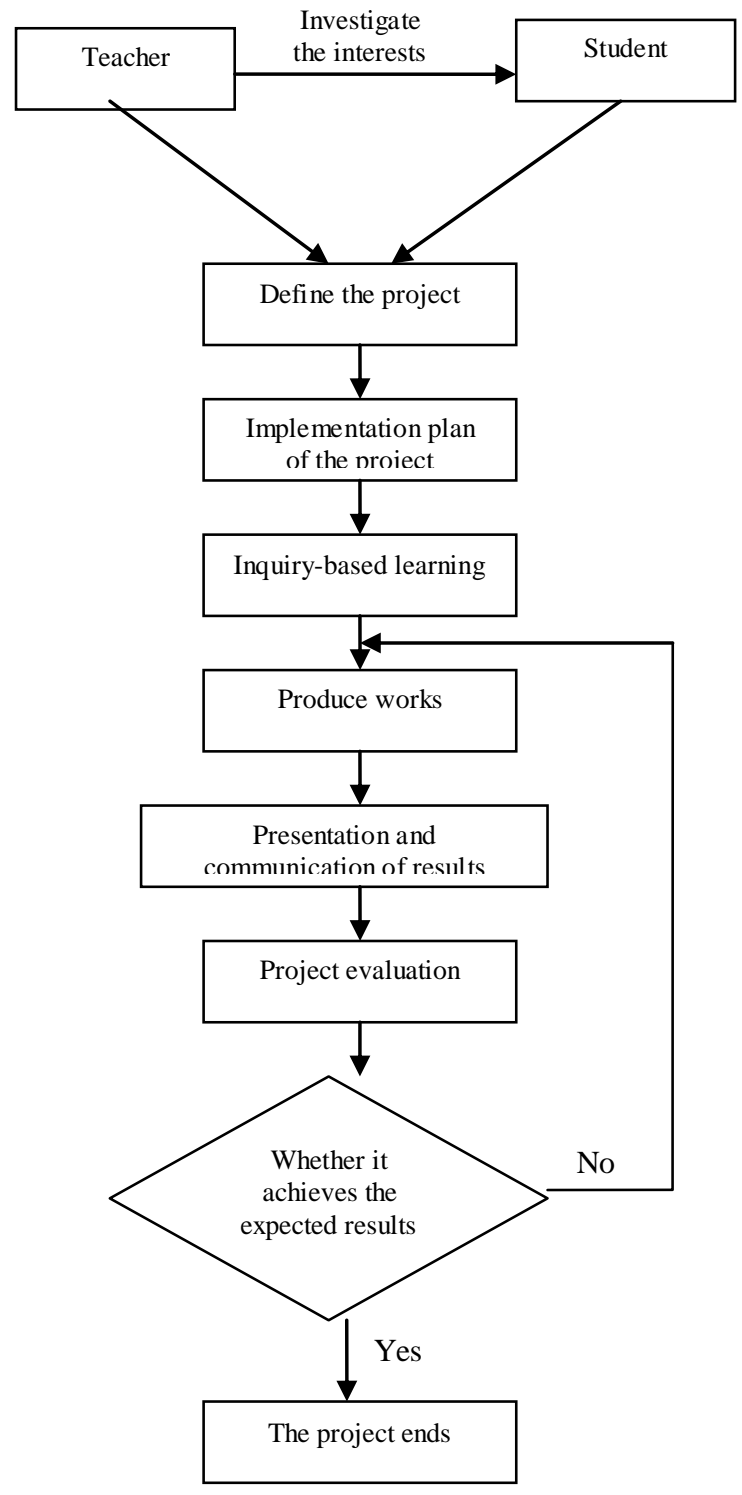

Fig. 1. Flow chart of PBL design.

1. Teachers investigate students' interests in order to determine a project that can reflect real problems and in which students are interested "Fig. 1".

2. The determination of project bases on curriculum standard and three-dimensional learning objectives. The themes proposed by students are screened and classified according to the autonomy, practicality, exploration and innovation of projects. The three-dimensional learning objectives include knowledge and skill, process and method, emotional attitude and values. Knowledge refers to facts, concepts, principles and rules. Skills include action skill and skills of observation, reading, calculation and investigation. Processes and methods include the process and method of scientific inquiry and the interpersonal communication in the cognitive process. Emotional attitude and values include the 
emotions, attitudes and value judgment toward themselves, others, nature and the mutual relationship.

3. The project implementation plan includes the time plan, unit plan, and assessment plan and personnel assignment. Time plan is a schedule to define the class hour of the whole project and the plan of project after the completion of each class, in order to supervise the execution time of the project. Unit plan defines the curriculum standards of each unit and what are the specific three-dimensional learning objectives. The design includes problems of curriculum framework of basic problem, unit problem and content problem. The evaluation plan refers to the evaluation timeline of V10 course in Intel Teach to the Future.

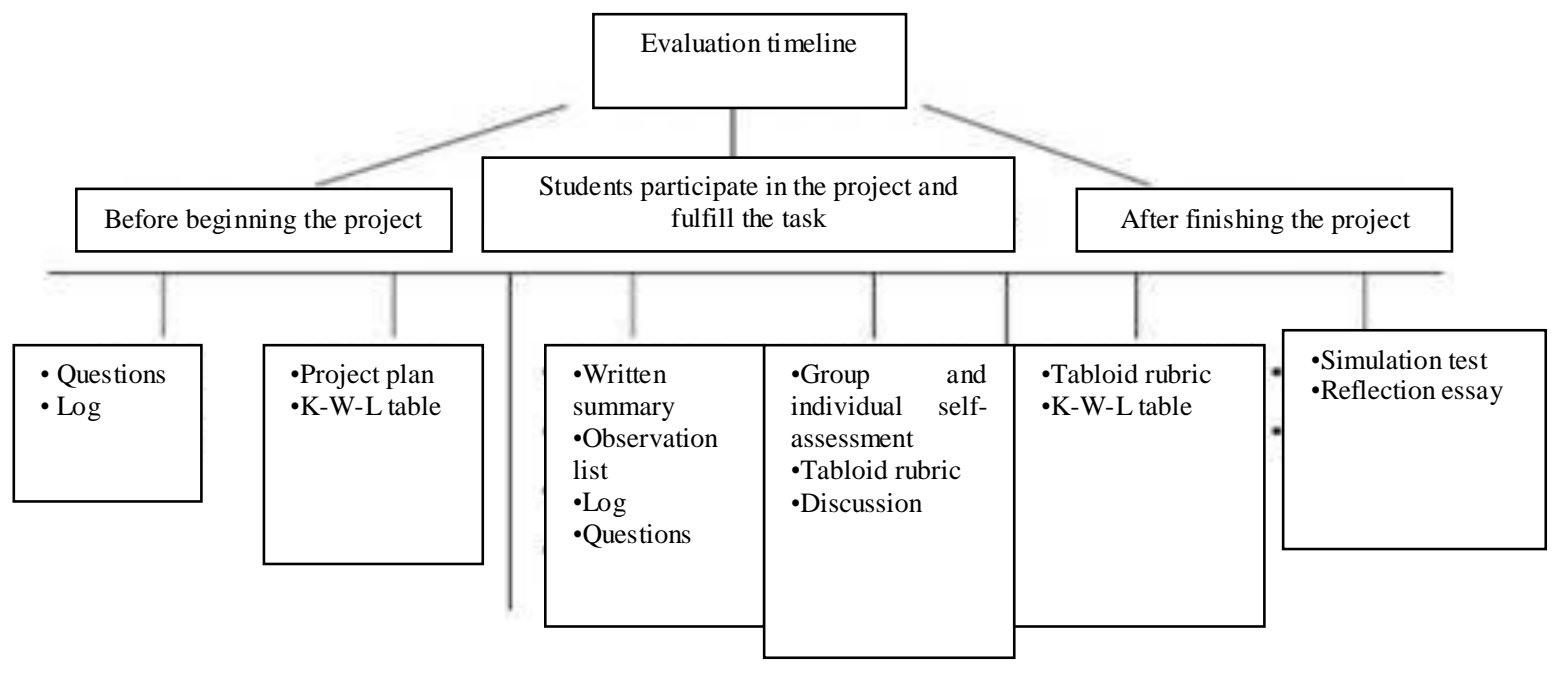

Fig. 2. Timeline of course evaluation in Intel Teach to the Future.

According to time period "Fig. 2", the evaluation is divided into pre-project assessment, process assessment and summative assessment of PBL. The pre-project assessment avails the determination of students' background knowledge, skills, attitudes and misunderstanding. Process assessment assesses students' requirements, monitors the progress and checks the understanding, encourages meta-cognition, independent learning and cooperation and embodies in the communication in working process of the project. The summative assessment assesses students' understanding and skills as well as requirements and encourages meta-cognition. Students have been grouped in the determination of the project. The personnel assignment refers to the work of each student in each group, such as look up the information, collect data, process and post production.

4. Inquiry learning and work production often mingle. Students explore the methods to produce works and put it into practice to complete the work. They will find problems and seek ways even shortcuts to solve problems, which realize the "combination of learning and doing". It makes the classroom more active and reaches one of the requirements of ecological classroom.

5. There are many ways to show the results such as ppt, word and webpage after discussion of group members. Students can communicate through seminar. When showing works, each group can recommend one representative to explain the method and skills to create the work. In order to train logical thinking, students can communicate connotation of the theme and humanistic spirit of the work.

6. The project implementation plan is applied to design the summative assessment and assess the work in the project.
The communication behavior between students and teachers are divided into dominative contacts and integrative contacts. Teachers' behaviors in the former include commanding, threatening, reminding and punishing; teachers' behaviors in the latter include agreeing, appreciating, accepting and effectively assisting. When teachers' behaviors are dominative, students have more difficulties in completing the schoolwork, obey teachers' leadership and sometimes violate strongly. When teachers' behaviors are integrative, students can solve problems spontaneously and are willing to make contributions to the group. [7] Therefore, on the basis of democracy and equality, the multiple assessments related to students and teachers in ecological classroom should pay attention to agreement, appreciation and acceptance, so that students can refer to each other in improvement of the work. Meanwhile, it trains students' independent and creative ability.

7. After the communication, teachers and students determine whether the work needs improvement. If it needs, turn to step four; if not, the project ends.

\section{CONCLUSION}

Ecological classroom is a form of classroom. The ecological index of the classroom reflects the health degree of it. As a method of organization teaching, PBL embodies the transformation of teaching pattern and changes students' abstract analysis and logical deduction on knowledge. The combination of the two is to improve the validity and reliability of classroom. Compared with the previous teaching, the integration of project-based learning in ecological classroom can improve learning effects and students' ability of independent exploration and cooperative 
learning. However, the project screening and the design of evaluation on teaching process need repeated improvement in the future research.

\section{REFERENCES}

[1] Li Qi. Effective Strategies for Classroom Teaching under the Background of New Course [M], Capital Normal University Press, 2006

[2] Xu Jinsheng, Wu Xiaojun. Project-based Learning - Exploration on Comprehensive Teaching Pattern [M], Zhejiang University Press, 2012

[3] Luo Jiutong. Research on Effectiveness and Influence Factors of Flipped Classroom Based on the Project-based Learning [D], East China Normal University, 2015

[4] Yang Chuanyu. Research on Interactive Teaching of Ecological Classroom Related to Chemistry in Junior High School, Suzhou University, 2013

[5] Xie Jianping. Research on Cases of Mathematical Ecological Classroom under the New Curriculum Concept [D], Gannan Normal University, 2013

[6] Yang Liping. Design and Development on Resource Library of Experimental Curriculum of Modern Educational Technology Based on Project-based Teaching [D], Hunan Normal University, 2016

[7] Duan Changong. Case Analysis of Effectiveness of "Project-based Teaching" in Higher Vocational Education [D], Suzhou University, 2015

[8] Investigation on Current Situation of Ecological Unbalance in Class of Music Teachers [J], Zhang Yi, Home Drama, 2017 (03) 